Conference Proceedings Paper

\title{
An Analysis of Ecological Indicators Applied to Agricultural Ecosystems: What to Retain to Shape a Future Indicator for Pol- linators ${ }^{+}$
}

\author{
Sergio Albertazzi ${ }^{1}$, Elisa Monterastelli ${ }^{2}$, Manuela Giovanetti ${ }^{1 *}$, Simone Flaminio ${ }^{1}$, Emanuele Luigi Zenga ${ }^{1}$, Laura \\ Bortolotti ${ }^{1}$ and Marino Quaranta ${ }^{1}$
}

Citation: Lastname, F.; Lastname, F.; Lastname, F. An Analysis of Ecological Indicators Applied to Agricultural Ecosystems: What to Retain to Shape a Future Indicator for Pollinators.

Published: 16 March 2021

Publisher's Note: MDPI stays neutral with regard to jurisdictional claims in published maps and institutional affiliations.

Copyright: (c) 2021 by the authors. Submitted for possible open access publication under the terms and conditions of the Creative Commons Attribution (CC BY) license (http://creativecommons.org/licenses/by/4.0/).
1 CREA Research Centre for Agriculture and Environment, Via di Corticella 133, 40128 Bologna, Italy; sergio.albertazzi@crea.gov.it; manuela.giovanetti@crea.gov.it; simone.flaminio@crea.gov.it; emanuele.zenga@crea.gov.it; laura.bortolotti@crea.gov.it; marino.quaranta@crea.gov.it

2 Independent Researcher, Via di Corticella 85, 40128 Bologna, Italy: elisa.monterastelli@gmail.com Correspondence: manuela.giovanetti@crea.gov.it

+ Presented at the 1st International Electronic Conference on Biological Diversity, Ecology, and Evolution, 1531 March 2021.

\begin{abstract}
Biodiversity loss has been demonstrated to have direct impacts on human welfare. However, policymakers need to refer to commonly accepted standards to monitor biodiversity, especially to direct fund granting. Intending to collate information for the creation of a reliable pollinators' one, we screened available indicators. Our first criterion was selecting indicators applied in agricultural contexts and legitimated by a regulatory agency. Further, we included indicators referring to any arthropod taxa and officially recognized at least by national bodies. We compared survey scale, monitoring scheme, type of environment, sampling effort, expected arthropod population, taxonomic level of data. As a common approach, we identified the combination of a territorial analysis by remote tools (e.g., GIS) and animal taxa surveys. The strength of indicators including arthropods emerges in the simultaneous inclusion of biotic and abiotic components. However, most of them just refer to confined environments (e.g., grasslands, riversides). Pollinators' sensitivity to changes at the micro-habitat level is widely recognized, even helping to distinguish different methods of agricultural management. To develop a biodiversity indicator based on pollinators, we suggest improving knowledge on local pollinator species and their environmental requirements, coupled with wide (in time and space) national monitoring programs..
\end{abstract}

Keywords: biodiversity; agroecosystems; arthropods; environment; pollinators; indicators; RDPs measures

\section{Introduction}

The biodiversity of the agroecosystems is becoming a crucial component in European legislation since it represents a key to tackle food security, human and environmental health, and climate change. A specific objective of the CAP post-2020 (European Common Agriculture Policy 2014-2020) is "to contribute to the protection of biodiversity, strengthen ecosystem services and preserve habitats and the landscape"[1]. Measuring biodiversity in agricultural systems is not effortlessly. For RDPs (EU countries Rural Development Programmes) actions to sustain biodiversity, FBI (Farmland Bird Index) and HNV (High Nature Value) farming were the adopted indicators [2]. However, they encountered some objections; therefore, HNV farming will not be integrated into the next CAP post-2020 [3], while the FBI, even if retained, proved to be poorly tied to local RDP measures [4]. So far, 
there is no tool to assess the impact of RDPs on biodiversity at the farm-level, despite an intensive research effort to identify suitable indicators [5].

Pollinators are desirable candidates to contribute to indicators applied to monitor the trend of biodiversity loss [6]. Their role in agroecosystems is recognized of crucial importance: they perform services in support of food production [7] and indirectly inform on pollutants and environmental quality [8]. Furthermore, the decline that pollinators are undergoing [9] can precisely impact agriculture produce [10]. The EU Biodiversity Strategy for 2030 focus on the decline of pollinators to reverse this trend [11] and a European group of experts is working on the methodologies to be adopted by a wide EU Pollinator Monitoring Scheme at a continental level [12]. Following the 2018 European Pollinator Initiative [13], the 2019 Directive on the conservation of biodiversity of the Ministry for Environment, Land and Sea Protection of Italy [14] provided funding and enhanced research on pollinator populations in Italian National Parks, with special acknowledge of threats driven by agricultural practices. ISPRA highlights the complexity of approaching pollinators as indicators with some in-situ sampling and by applying a simple-level taxonomic recognition [15]. Our research group is involved in two projects: the European LIFE 4 POLLINATORS, led by the Alma Mater Studiorum (University of Bologna), and the national BeeNet, led by CREA (Research Centre for Agriculture and Environment), both related to pollinators in agricultural environments. One of the objectives of the first is evaluating agroecosystems in the intensely-cultivated area of the Po Valley [16] through pollinator monitoring and direct involvement of farmers. The second is applying a large monitoring scheme on honeybees and wild bees at the regional level all over the country. Data should all contribute to testing a pilot indicator (in progress), that also acknowledges EU recent guidelines on pollinator monitoring. While carrying out data collection, these projects face gaps in our comprehension of pollinators' ecology, especially that of bees (Apoidea, [12]). Missing information on species-specific requirements are frequent, as confirmed by the European red list: about $56 \%$ of species are indicated as "data deficient" [17]. Therefore, we suggest that a potential starting point to address a future pollinatorbased indicator is identifying and analyzing the structure of other indicators applied to investigate biodiversity.

Greening measures have been implemented to counteract biodiversity loss, especially through fund granting. However, evaluating the resulting impact of these actions, and consequently, the financial effort linked to them, has not been successful so far. Our long-term goal is to define an indicator based on pollinators and able to highlight the power of greening measure and RDPs contribution. This indicator should therefore inform policymakers by highlighting and sustaining effective measures. To achieve that, we are presenting an analysis of existing indicators, underlining their power and their weakness, and discussing what to retain.

\section{Methods}

In temperate latitudes, the pollination service is carried out mainly by insects [12]. Among existing indicators, we considered those including the evaluation of biodiversity in agroecosystems and arthropods as bio-indicator organisms. There are numerous indexes/indicators proposed to evaluate the agroecosystem. We applied another filter, selecting those that have been legitimated (through a protocol approved by a scientific regulatory agency) or officially recognized (through their inclusion in regulation and therefore considered the official method in the given context; Figure 1). 


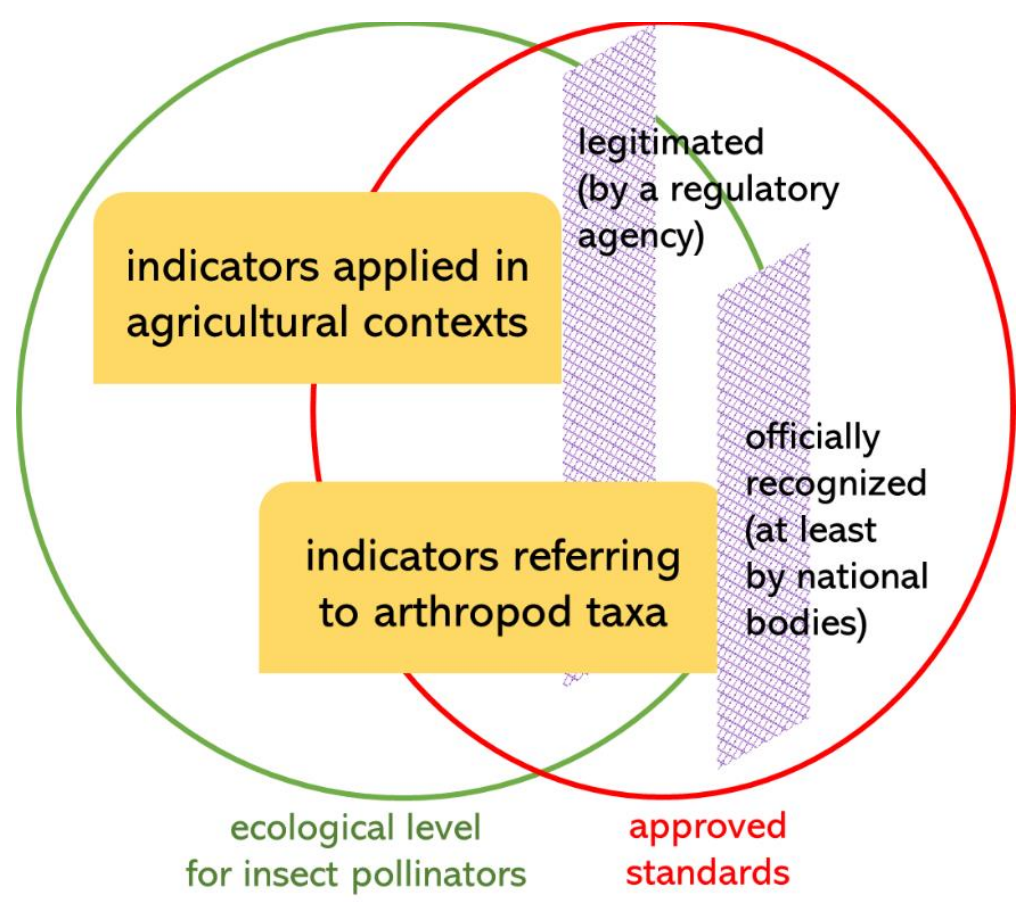

Figure 1. Criteria we applied to select existing indexes/indicators to be compared, to contribute to developing a future biodiversity indicator based on pollinators. On the one hand, indicators need to be suitable for agroecosystems, or for investigating arthropod taxa so to maintain similarity with insect pollinators of temperate areas. On the other, indicators need to have already passed a "political" filter: legitimated by a regulatory agency and/or officially recognized by (at least) a national body, to ensure a proven interest from a legislative point of view.

The following are the definitions we will employ further on.

Index and indicator. We define "index" an instrument that returns a value to describe a measurable phenomenon (e.g., the sampled population against the expected one). "Indicator" is a more complex and often composed instrument, aimed at evaluating a phenomenon not directly measurable.

Key criteria. a) the evaluation of biodiversity in agroecosystems and b) arthropods as bio-indicator organisms. We surveyed reports of the European Environment Agency (EEA); the indexes and/or indicators included in the Italian "Testo Unico Ambientale" (D. Lgs. no. 152/2006) [18], a text adopting numerous European directives on environmental issues; protocols drawn up by ISPRA; and finally, Italian regional legislation [19].

Legitimated vs. officially recognized. To be legitimated, an index/indicator need to be tested by a scientific regulatory agency, that possibly further create and publish an official protocol for its implementation: it is therefore the result of a technical-scientific approach. To be officially recognized, an index/indicator need to be included in an existing regulation: it is the results of authorization for its use in a legal framework.

We proceeded by a bibliographic search, through official websites of the regulatory agencies: the scientific ones that are responsible for the development and legitimation of indicators, and the political ones responsible for the recognition of biodiversity indicators in regional, national, or European legislation.

We analyzed each index/indicator by the following parameters:

1. Taxonomic groups: the taxa of the subject species and their ecological/biological resemblance with pollinator lifestyles.

2. Spatial context: definition of the spatial scale (regional, local, codified habitats, portions of habitats) and of parameters applied to define it, arbitrary or ecological (i.e: the application of a rigid sampling scheme, adaptation of the sampling scheme to territorial characteristics, individual case studies). 
3. Baseline background: level of ecological/biological knowledge on the subject species, (i.e.: is there is an expected population/list of species typical of a given habitat in the absence of disturbance?).

4. Sampling effort and level of taxonomic identification: type of sampling protocol and subsequent taxonomic effort; the taxonomic level of identification; skills required for these activities.

5. Final output: quantity and type of outputs (i.e.: descriptive, or class/category).

\section{Results}

We selected eight indexes/indicators potentially useful for the further development of an indicator on pollinators. Three of them are linked to the first key criterion (the evaluation of biodiversity in agroecosystems) and the other five to the second (arthropods as bio-indicator organisms). The main characteristics of these indexes/indicators are summarized in Table 1.

Table 1. List of selected indexes and indicators, with information on regulatory agencies (European, Italian, or regional) and year of official release.

\begin{tabular}{|c|c|c|c|}
\hline Indicator/index & Acronym & Legitimated & Officially recognized \\
\hline Farmland Bird Index & FBI & EEA/2005 [20,21] & CAP (from 2000 to post-2020) $[2,3,22]$ \\
\hline $\begin{array}{l}\text { High Natural Value } \\
\text { Farming }\end{array}$ & HNV farming & EEA/2004 [23,24] & CAP (from 2007 to 2020 ) \\
\hline Proxy & PrY & EEA/2019 [25,26] & CAP post-2020 [3] \\
\hline $\begin{array}{l}\text { Fresh water macrobenthos } \\
\text { index }\end{array}$ & STAR ICMI & ISPRA/2014 [27] & Directive 2000/60/EC [28] \\
\hline Grassland Butterfly Index & GBI & EEA/2013 [29-32] & none \\
\hline $\begin{array}{l}\text { Soil Macrobenthos } \\
\text { Index }\end{array}$ & QBS-ar & $(\text { CREA, ISPRA })^{2}$ [33-35] & Emilia-Romagna Region (from 2015) [19] \\
\hline Sirph the Net & STN & ISPRA/2015 [36,37] & none \\
\hline Ground beetle index & GrB & ISPRA $/ 2005^{3}[38-40]$ & none \\
\hline
\end{tabular}

Notes: ${ }^{1}$ Implicitly officially recognized, as it is included into HNV farming; ${ }^{2}$ agencies names in parenthesis since legitimation in progress; ${ }^{3}$ ISPRA protocol establishes a standard for sampling but does not establish the indicator.

The result of our analysis for each parameter follows:

1. Taxonomic groups. Among the eight indexes/indicators, we found all taxa of pollinators. As taxa of pollinators, we consider the ones included by the EU recent guidelines on pollinator monitoring: e.g., bees, butterflies, flies. GBI, HNV farming and PrY focused on butterflies; STN and PrY (but the list in progress [41]) on hoverflies and PrY also included bees. However, not all groups were considered at the same level of detail. For butterflies and hoverflies, all species are considered; for bees, only endangered species.

2. Spatial context. The spatial analysis ranges from largely adopted European monitoring plans to individual case studies. FBI, GBI and STAR-ICMI are based on monitoring programs defined respectively by the European Bird Census Council (EBCC), the European Butterfly Monitoring Scheme (eBMS) and the Directive 2000/60 / EC. FBI considers the whole European territory, divided into regular grids. GBI and STAR-ICMI focus on a portion of the continent containing given environments (pastures and hydrographic basins). The other indicators try to standardize individual case-studies by correlating the results with the characteristics of the habitat (SNT, QBS-ar), or by varying the sampling methodology (GrB).

3. Baseline background. Knowing the ecology and biology of target species is very important. PrY considers the rate of extinction risk, while STAR-ICMI and QBS-ar the morphometric adaptations to individual microhabitats. The link of target taxa with the environment in which they live may be expressed by an indirect parameter as the land use 
(Corine Land Cover) on a cartographic level. Some indexes are structured to combine with other tools to resume more baseline information, forming a macro-indicator. In the "Testo Unico Ambientale" (D. Lgs. 152/2006), that integrates the Directive 2000/60/CE, the STARICMI index is combined with other biological indexes (on fishes, macrophytes, diatoms) to define the Ecological Index of Biotic Quality (EQB). EQB also include the sensitivity to pollutants and hydro-morphological aspects for an overall assessment of environmental quality.

4. Sampling effort and taxonomic identification. Sampling effort is established by monitoring protocols, while taxonomic identification can be carried out in the field or back in the laboratory. EBCC monitoring plans include a different pool of bird species in each country (230 nesting species in the case of Italy). eBMS investigates 435 European butterfly species, identified at species level directly in the field. Both are coordinated and supervised by regulatory agencies through the work of thousands of trained professional and volunteers. An opposite situation is that of samplings that later require identification in the laboratory through an optical microscope (STAR-ICMI, QBS-ar, STN, GrB). Another parameter that may vary is the type of collected data: abundance (FBI, GBI), or presenceabsence (occupancy) (STN, HNV farming, PrY, STAR ICMI, GrB, QBS-ar).

5. Final output. Usually, indexes compare a resulting value with a reference: for FBI the reference is the corresponding value in a given year (2000 for Italy); for HNV farming and $\operatorname{PrY}$ the reference is the entire area of the farm. It could also be a given population (STN, STAR ICMI, GrB, FBI). Ideally, the value of the index indicates the disturbance suffered by the environment and recorded by the sampled population. FBI and GBI consider a few species: 23 and 17, respectively (for the latter: 10 generalists and 7 specialists). In some cases, only expert opinion can interpret rough data and estimate the disturbance (GrB). In other cases, indexes transform the data into a well-defined qualitative scale (STAR-ICMI,), or a set of user-friendly values so that also non-experts can compare results on a national / European basis (QBS-ar and STN).

\section{Conclusion}

Pollinator taxa are different among themselves, in their ecological requirements and their interactions with the landscape. In the framework of a future indicator on pollinators, we depicted as an important variable to be considered that of a cartographic analysis of the territory. It is crucial to choose a level that complies with 1) the reduced mobility of pollinators, and 2) the spot-distribution of RDPs fund granting. Therefore, actual tools that include information on land use into indicators need to be sharpened to greater detail. To overcome the deep gaps in our knowledge on (some) pollinators biology and ecology, we suggest broadening the environmental parameters possibly by building a complex indicator based on several indexes. Among them, those more strictly linked with pollinators should be included (e.g., vegetation type, crops, agricultural practices, climatic context, etc.). We should also care about the relationship between environmental parameters and the target taxa of pollinators. For example, butterflies and hoverflies are linked to vegetation especially as food for the larval stages (not mobile). On the contrary, adult bees are the ones more strictly connected to vegetation and interested in a wider (flight) range. The necessary ability for taxonomic identification has been already recognized as a limiting factor. It may limit the possibility of introducing, into the indicator, the expected population of a species and identifying different ecological weights for each species of taxa. In some cases, a reduced number of species can be selected and included in the indicator. For example, species that showed a sensitivity to the use of pesticides can be the main target, or those differently reacting to given agricultural practices. The ideal situation to achieve in the future would be to integrate information on abundancy and occupancy of sampled species, widening the range of legitimated methodologies.

All the above is feasible if pursuing extensive (both in terms of space and time) monitoring programs, that may also include public awareness-raising from citizen science projects. The latter have been widely adopted in many research fields to increase/facilitate the 
sampling effort [42]. We compared indexes/indicators tested in the field for a long time and any new indicator is expected to undergo the same path. Many established indicators (QBS-ar, GrB) are equally undergoing a refinement phase even promoted by regulatory agencies and pilot studies. An indicator based on pollinators is achievable and will certainly contribute to measuring the biodiversity of the agroecosystems.

Acknowledgments: We are indebted to Dr. Antonella Trisorio (CREA "Agricultural Policies and Bioeconomy") who provided updated information and important material to revise. The present study is partly funded by BeeNet 2019-2023 (Italian National Fund under FEASR 2014-2020 by the MIPAAF "Ministry for Environment, Land and Sea Protection" to the CREA "Research Centre for Agriculture and Environment"), and by the project "LIFE 4 POLLINATORS" (LIFE18 GIE /IT/000755).

Author Contributions: Conceptualization, S.A., E.M.; methodology, S.A., E.M., M.G.; literature analysis, S.A., E.M., S.F., E.L.Z.; writing - original draft preparation, S.A., E.M.; writing - review and editing, M.G., L.B, M.Q.; visualization, S.A., E.M., M.G.; supervision, M.G., L.B, M.Q.; funding acquisition, L.B, M.Q. All authors have read and agreed to the published version of the manuscript.

Conflicts of Interest: The authors declare no conflict of interest.

\author{
Abbreviations \\ The following abbreviations are used in this manuscript: \\ EU: European Union \\ CAP: (European) Common Agriculture Policy \\ RDPs: (EU countries) Rural Development Programmes \\ FBI: Farmland Bird Index \\ HNV farming: High Nature Value farming \\ ISPRA: (Italian) National Institute for Environmental Protection and Research \\ GIS: Geographical Information System \\ CREA: (Italian) Council for Agricultural Research and Economics (in this context, with its Research \\ Centre for Agriculture and Environment) \\ EEA: European Environment Agency \\ D. Lgs.: decreto legislative (legislative decree) \\ STAR-ICMI: Fresh water macrobenthos index \\ GBI: Grassland Butterfly Index \\ QBS-ar: Soil macrobenthos Index \\ STN: Sirph the Net (Syrphidae) \\ GrB: Ground beetle index \\ EBCC: European Bird Census Council \\ eBMS: European Butterfly Monitoring Scheme \\ EQB: Ecological Index of Biotic Quality
}

\title{
References
}

1. European Commission Proposal for a Regulation of the European Parliament and of the Council Establishing Rules on Support for Strategic Plans to Be Drawn up by Member States under the Common Agricultural Policy (CAP Strategic Plans) and Financed by the European Agricultural Guarantee Fund (EAGF) and by the European Agricultural Fund for Rural Development (EAFRD) and Repealing Regulation (EU) No1305/2013 of the European Parliament and of the Council and Regulation (EU) No 1307/2013 of the European Parliament and of the Council COM(2018) 392; 2018;

2. Directorate-General for Agriculture and Local Development Technical Handbook on the Monitoring and Evaluation Framework of the Common Agricultural Policy 2014-2020; European Commission Directorate-General for Agriculture and Local Development, 2017; p. 85; 
3. European Commission The Post-2020 Common Agricultural Policy: Environmental Benefits and Simplification. 2019.

4. Calvi, G.; Campedelli, T.; Tellini Florenzano, G.; Rossi, P. Evaluating the Benefits of Agri-Environment Schemes on Farmland Bird Communities through a Common Species Monitoring Programme. A Case Study in Northern Italy. Agricultural Systems 2018, 160, 60-69, doi:10.1016/j.agsy.2017.09.002.

5. Dennis, P.; Arndorfer, M.; Balázs, K.; Bailey, D.; Boller, B.; Bunce, R.G.H.; Centeri, C.; Corporaal, A.; Cuming, D.; Deconchat, M. BIOBIO: Indicators for Biodiversity in Organic and Low-Input Farming Systems. Work Package 2009, 2.

6. Kevan, P.G. Pollinators as Bioindicators of the State of the Environment: Species, Activity and Diversity. $1999,21$.

7. Rader, R.; Bartomeus, I.; Garibaldi, L.A.; Garratt, M.P.D.; Howlett, B.G.; Winfree, R.; Cunningham, S.A.; Mayfield, M.M.; Arthur, A.D.; Andersson, G.K.S.; et al. Non-Bee Insects Are Important Contributors to Global Crop Pollination. Proc Natl Acad Sci USA 2016, 113, 146-151, doi:10.1073/pnas.1517092112.

8. Porrini, C.; Sabatini, A.G.; Girotti, S.; Ghini, S.; Medrzycki, P.; Grillenzoni, F.; Bortolotti, L.; Gattavecchia, E.; Celli, G. Honey Bees and Bee Products as Monitors of the Environmental Contamination. Apiacta 2003, 38, 63-70.

9. Kluser, S.; Peduzzi, P. Global Pollinator Decline: A Literature Review. 2007.

10. Gallai, N.; Salles, J.-M.; Settele, J.; Vaissière, B.E. Economic Valuation of the Vulnerability of World Agriculture Confronted with Pollinator Decline. Ecological economics 2009, 68, 810-821.

11. European Commission Biodiversity Strategy for 2030 Bringing Nature Back into Our Lives COM(2020) 380; 2020;

12. Potts, S.G.; Dauber, J.; Hochkirch, A.; Oteman, B.; Roy, D.; Ahrne, K.; Biesmeijer, K.; Carvell, C.; Ferreira, C.; Fitzpatrick, U.; et al. Proposal for an EU Pollinator Monitoring Scheme. 2020, 352.

13. European Commission EU Pollinators Initiative COM (2018) 395; 2018;

14. Ministero dell'Ambiente Decreto Ministeriale n. 43 Del 26/02/2019. Direttiva Generale Contenente Le Priorità Politiche e l'indirizzo per Lo Svolgimento Dell'azione Amministrativa e per La Gestione Del Ministero Dell'Ambiente per 1'anno 2019.; 2019;

15. ISPRA; Ministero dell'Ambiente; Arpa Piemonte; Università degli Studi di Roma Tor Vergata; Università degli Studi di Torino Metodi Di Campionamento Proposti per l'attuazione Dei Progetti per Il Monitoraggio e La Tutela Degli Impollinatori Nei Parci Nazionali (Direttiva Del Ministero Dell'Ambiente 2019) 2020.

16. LIFE 4 Pollinators "Involving People to Protect Wild Bees and Other Pollinators in the Mediterranean" Available online: https://www.life4pollinators.eu/ (accessed on 20 February 2021).

17. Nieto, A.; Roberts, S.P.M.; Kemp, J.; Rasmont, P.; Kuhlmann, M.; García Criado, M.; Biesmeijer, J.C.; Bogusch, P.; Dathe, H.H.; De la Rúa, P.; et al. European Red List of Bees.; Publications Office: Luxembourg, 2014; ISBN 978-92-79-44512-5.

18. Presidente della Repubblica Decreto Legislativo 3 Aprile 2006, n. 152 Norme in Materia Ambientale; 2006;

19. Proprietà e qualità dei suoli Available online: https://ambiente.regione.emilia-romagna.it/it/geologia/suoli/proprieta-e-qualitadei-suoli (accessed on 20 February 2021).

20. Gregory, R.D.; van Strien, A.; Vorisek, P.; Gmelig Meyling, A.W.; Noble, D.G.; Foppen, R.P.B.; Gibbons, D.W. Developing Indicators for European Birds. Phil. Trans. R. Soc. B 2005, 360, 269-288, doi:10.1098/rstb.2004.1602.

21. EEA, O. Agriculture and Environment in the EU-15-the IRENA Indicator Report. EEA, Copenhagen 2005.

22. European Council Council Decision of 20 February 2006 on Community Strategic Guidelines for Rural Development (Programming Period 2007 to 2013) (2006/144/EC) (OJ L 55, 25.2.2006, p. 20); 2006;

23. EEA High Nature Value Farmland - Characteristics, Trends and Policy Challenges; European Environment Agency: Copenhagen, 2004; p. 32;.

24. Maria Luisa Paracchini; Jan-Erik Petersen; Ybele, Hoogeveen; Catharina Bamps; Ian Burfield; Chris van Swaay High Nature Value Farmland in Europe: An Estimate of the Distribution Patterns on the Basis of Land Cover and Biodiversity Data; European Commission. Joint Research Centre. Institute for Environment and Sustainability. European Environment Agency: Luxembourg, 2008; 
25. Antonella Trisorio; Paola Lauricella L'Italia e La PAC Post 2020 - Policy Brief 6. OS6: Contribuire Alla Tutela Della Biodiversità, Rafforzare i Servizi Ecosistemici e Preservare Gli Habitat e Il Paesaggio, Rete Rurale Nazionale 2014-2020.; Rete Rurale Nazionale 2014-2020; Mipaaf: Roma, 2019; p. 58;

26. Working Document Defining Proxy Indicators for Rural Development Programmes; European Evaluation Network for Rural Development, 2014;

27. ISPRA - Gruppo di Lavoro 'Metodi Biologici' Metodi Biologici per Le Acque Superficiali Interne; Manuali e Linee Guida; ISPRA - Settore Editoria: Roma, 2014; ISBN 978-88-448-0651.

28. European Parliament; European Council Directive 2000/60/EC of the European Parliament and of the Council of 23 October 2000 Establishing a Framework for Community Action in the Field of Water Policy; 2000; Vol. OJ L;

29. Van Swaay, C.; van Strien, A. Using Butterfly Monitoring Data to Develop a European Grassland Butterfly Indicator. Studies on the ecology and conservation of Butterflies in Europe. Vol 1: General concepts and case studies 2005, 106-108.

30. Van Swaay, C.; van Strien, A.; Harpke, A.; Fontaine, B.; Stefanescu, C.; Roy, D.; Kühn, E.; Õnuao, E.; Regan, E.; Švitra, G. The European Grassland Butterfly Indicator: 1990-2011. EEA Technical Reports 2013, 11.

31. Van Swaay, C.A.; Dennis, E.B.; Schmucki, R.; Sevilleja, C.G.; Balalaikins, M.; Botham, M.; Bourn, N.; Brereton, T.; Cancela, J.P.; Carlisle, B. The EU Butterfly Indicator for Grassland Species: 1990-2017: Technical Report. Butterfly Conservation Europe \& ABLE/eBMS. www. butterfly-monitoring. net 2019.

32. Van Swaay, C.; Dennis, E.; Schmucki, R.; Sevilleja, C.; Aghababyan, K.; Astrom, S.; Balalaikins, M.; Bonelli, S.; Botham, M.; Bourn, N. Butterfly Indicators 1990-2018. Technical Report. 2020.

33. CTNTES La Conoscenza Della Qualità Del Suolo Attraverso l'utilizzo Di Indicatori Biologici Ed Ecotossicologici. In Proceedings of the Atti del Convegno Nazionale di Torino del 13 maggio 2004; 2004; p. 83.

34. Parisi, V.; Menta, C.; Gardi, C.; Jacomini, C.; Mozzanica, E. Microarthropod Communities as a Tool to Assess Soil Quality and Biodiversity: A New Approach in Italy. Agriculture, ecosystems \& environment 2005, 105, 323-333.

35. Gruppo di lavoro QBS della Società Italiana della Scienza del Suolo Available online: https://www.crea.gov.it/web/foreste-elegno/-/gruppo-di-lavoro-qbs-della-societ\%C3\%A0-italiana-della-scienza-del-suolo (accessed on 24 February 2021).

36. Burgio G., Sommaggio D., Birtele D. ISPRA I Sirfidi (Ditteri): Biodiversità e Conservazione.; Manuali e Linee Guida; ISPRA: Bologna, 2015;

37. Sommaggio, D.; Burgio, G. The Use of Syrphidae as Functional Bioindicator to Compare Vineyards with Different Managements. Bulletin of Insectology 2014, 67, 147-156.

38. Brandmayr, P.; Agenzia per la protezione dell'ambiente e per i servizi tecnici I coleotteri carabidi per la valutazione ambientale e la conservazione della biodiversità: manuale operativo; APAT: Roma, 2005; ISBN 978-88-448-0152-6.

39. Cosimi, S.; Rossi, E. I Coleotteri Carabidi come bioindicatori nell'agroecosistema: un caso di studio all'interno del Centro Interdipartimentale di Ricerche Agro-ambientali “Enrico Avanzi.” 2013, 11, 86.

40. Langraf, V.; Petrovičová, K.; David, S.; Nozdrovická, J.; Petrovič, F.; Schlarmannová, J. The Bioindication Evaluation of Ground Beetles (Coleoptera: Carabidae) in Three Forest Biotopes in the Southern Part of Central Slovakia. Ekológia (Bratislava) 2019, 38, 2536, doi:10.2478/eko-2019-0003.

41. European Red List of Hoverflies Available online: https://www.iucn.org/regions/europe/our-work/biodiversity-conservation/european-red-list-threatened-species/european-red-list-hoverflies (accessed on 23 February 2021).

42. Newman, G.; Wiggins, A.; Crall, A.; Graham, E.; Newman, S.; Crowston, K. The Future of Citizen Science: Emerging Technologies and Shifting Paradigms. Frontiers in Ecology and the Environment 2012, 10, 298-304. 